\title{
Clinical analysis of patients with skeletal metastasis of lung cancer
}

\author{
Yong Jin Cho ${ }^{1}$, Yung Min Cho ${ }^{1}$, Sung Hyun Kim², Kyoo-Ho Shin ${ }^{2}$, Sung-Taek Jung ${ }^{3}$ and Hyo Song Kim ${ }^{*}$
}

\begin{abstract}
Background: Many factors influence bone metastases of lung cancer, and several studies report about survival of skeletal metastasis. However, few studies have focused on identifying the prognostic factors for skeletal metastasis of lung cancer, especially following orthopedic surgery. We conducted a retrospective analysis of the clinical characteristics of skeletal metastasis from lung cancer and discuss the prognostic factors.

Methods: We performed a medical record review of 202 patients who were diagnosed with skeletal metastasis from lung cancer. Adenocarcinoma was found in 116 patients (57.4\%), squamous cell carcinoma in 29 (14.4\%), small-cell lung cancer (SCLC) in 37 (18.7\%), and large-cell carcinoma and other types of cancer in 20 patients (9.9\%). Orthopedic surgery for skeletal metastasis was performed in 41 patients (20.3\%).

Results: Lung cancer survival was 12.1 months. After diagnosis of lung cancer, skeletal metastasis was found at a mean of 2.5 months, and skeletal metastasis survival was 9.8 months. Lung cancer survival in patients younger than 60 years was 13.8 months, and lung cancer survival in patients 60 years or older was 10.8 months $(p=0.009)$. Skeletal metastasis survival in patients younger than 60 years was 11.0 months, and skeletal metastasis survival in patients 60 years or older was 8.8 months $(p=0.002)$. Mean skeletal metastasis survival with surgery was 12.6 months and without surgery was 9.1 months $(p<0.000)$. In the multivariate analysis of lung cancer survival, age under 60 years [HR (95\% Cl) 1.549 (1.122-2.139), $p=0.008]$, non-small cell lung cancer pathology type [HR (95\% Cl) 1.711 (1.157-2. 532), $p=0.008$ ], chemotherapy for skeletal metastasis [HR (95\% Cl) 8.064 (3.981-16.332), $p<0.000$ ], and radiation therapy for skeletal metastasis [HR (95\% Cl) 1.791 (1.170-2.742), $p=0.007$ ] were significant, independent, good prognostic factors. In the multivariate analysis of skeletal metastasis survival, age under 60 years [HR (95\% Cl) 1.549 (1.124-2.134), $p=0.007]$, non-small cell lung cancer pathology type [HR (95\% Cl) $2.045(1.373-3.047), p<0.000]$, chemotherapy for skeletal metastasis [HR (95\% Cl) 7.121 (3.542-14.317), $p<0.000]$, and orthopedic surgical treatment for skeletal metastasis [HR $(95 \% \mathrm{Cl}) 1.710(1.148-2.547), p=0.008]$ were significant, independent, good prognostic factors.
\end{abstract}

Conclusions: Patients who survived longer were less than 60 years old, received chemotherapy as treatment for skeletal metastasis, had NSCLC rather than SCLC, and underwent orthopedic surgery for skeletal metastasis.

Keywords: Lung neoplasms, Multivariate analysis, Bone neoplasms

\section{Background}

Lung cancer is the leading cause of cancer-related deaths worldwide, accounting for almost $20 \%$ of cancer-related fatalities $[1,2]$. The incidence of lung cancer is about $53.6 / 100,000$ people every year, and mortality is $45.6 /$ 100,000 every year [3]. The skeletal system is one of the

\footnotetext{
* Correspondence: hyosong77@yuhs.ac

${ }^{4}$ Division of Medical Oncology, Department of Internal Medicine, Yonsei University College of Medicine, 134 Shinchondong, Seodaemun-gu, Seoul 120-752, South Korea

Full list of author information is available at the end of the article
}

most common distal metastatic sites in patients with lung cancer, and $30-40 \%$ of those with advanced lung cancer develop skeletal metastases $[4,5]$. Skeletal metastasis involves significant morbidity, metabolic disorders such as hypercalcemia, pathologic fractures, and spinal cord compression. These disease sequelae entail a reduction in quality of life and require costly treatments that have limited impact on overall survival. The importance of metastasis from lung cancer has been overlooked in patients with advanced lung cancer because the mean

(c) The Author(s). 2019 Open Access This article is distributed under the terms of the Creative Commons Attribution 4.0 International License (http://creativecommons.org/licenses/by/4.0/), which permits unrestricted use, distribution, and 
survival is less than 6 months [6]. The recent development of remarkable chemotherapy and supportive therapies has caused the average survival time in patients with lung cancer to dramatically increase, and interest in skeletal metastasis of lung cancer has increased. Pathologic fractures, or skeletal-related events (SREs), following the skeletal metastasis of lung cancer can substantially reduce quality of life and increase economic burden. Some reports have stated that the incidence of SREs are reduced with use of medications, such as bisphosphonates and denosumab, for lung cancer that has metastasized to the limbs of the skeletal system [7-10]. Traditionally, orthopedic surgery, such as open reduction internal fixation, has been an important treatment method. Many factors influence bone metastases of lung cancer, including age, sex, pathologic type, number of primary lesions, number of bone metastases, treatment regimens, and serum markers [11]. However, few studies have focused on identifying the prognostic factors for skeletal metastasis from lung cancer, especially following orthopedic surgery. Therefore, we conducted a retrospective analysis of the clinical characteristics of skeletal metastasis from lung cancer and discuss the prognostic factors.

\section{Methods}

\section{Participants}

From January 1, 2005 to December 31, 2015, a total 329 patients with lung cancer who were diagnosed with skeletal metastatic disease were recruited from three institutions. For the purpose of analysis, the following exclusion criteria were applied: 1) patients who had only spinal metastasis without appendix bone metastasis $(n=$ 82) and 2) patients who had undergone an operation on the small bones of the hands or feet $(n=3)$. Of the remaining 244 patients, 42 patients with less than 24 months of follow up were excluded, which left us with 202 patients for medical record review.

Of the total 202 patients, $126(62.4 \%)$ were male and $76(37.6 \%)$ were female. The mean age was 61.2 years (range: 29-85 years). Adenocarcinoma was found in 116 patients (57.4\%), squamous cell carcinoma in 29 (14.4\%), small-cell lung cancer (SCLC) in 37 (18.7\%), and large-cell carcinoma and other types of cancer in 20 patients (9.9\%). A total 114 patients (56.4\%) had a history of smoking at the time of diagnosis, and 88 (43.6\%) had no smoking history. Hypertension was diagnosed in 50 cases (24.8\%), and diabetic mellitus was 26 cases (12.9\%), chronic renal failure was 3 cases $(1.5 \%)$. Chemotherapy was administered in 192 cases (95.0\%) for skeletal metastasis from lung cancer, and radiation therapy was used in 174 cases $(86.1 \%)$ (Table 1). We reviewed plain radiography, magnetic resonance imaging (MRI), computed tomography (CT), whole body bone scan (WBBS), and positron emission tomography- computed tomography (PET-CT). When the patient's imaging results showed two or more positive findings, the patient was confirmed to have skeletal metastases. In 41 patients who underwent orthopedic surgery, pathologic examination of the metastatic site was performed. In all cases, metastatic lung cancer was reported. A typical example from diagnosis to progression, operation and the results was shown in Fig. 1. The patients were followed for 24 months in an open patients department visit and/or telephone interview. We analyzed the survival rate and prognostic factors of patients with lung cancer who had skeletal metastases (Table 1). Ethics approval was obtained from the Ethics Committee from all three participating hospitals.

\section{Statistical analysis}

The general characteristics and basic data of patients were summarized using descriptive statistics. The correlation between survival length after diagnosis of lung cancer, diagnosis of skeletal metastasis, and clinicopathologic variables was analyzed using an independent sample $t$-test. For survival analysis, lung cancer survival was defined as the time interval between the diagnosis of lung cancer and death or the last follow-up. Skeletal metastasis survival was defined as the time interval between the diagnosis of skeletal metastasis from lung cancer and death or the last follow-up. Lung cancer survival analyses and skeletal metastasis survival analyses were conducted according to the Kaplan-Meier method. Univariate and multivariate analyses were done using a proportional hazard regression model (cut-off $p$ value of 0.05 ). A multivariate analysis included significant and non-redundant variables selected from the univariate analysis [12]. All statistical analyses were carried out using IBM SPSS version 18.0 (SPSS Inc., Chicago, Illinois, USA). Results were considered statistically significant if $p<0.05$.

\section{Results \\ Demographic data}

A total of 128 patients (63.4\%) were found to have multiple distant metastases, including skeletal metastases, at the time of lung cancer diagnosis, and 35 patients $(17.3 \%)$ only had skeletal metastases at the time of lung cancer diagnosis. Epidermal growth factor receptor (EGFR) mutation was detected in $18 \mathrm{pa}$ tients $(8.9 \%)$ and not detected in 53 patients $(26.2 \%)$; EGFR mutation tests were not performed in the remaining 131 patients (64.9\%). There were 43 patients $(21.3 \%)$ with one other distant organ metastasis, 78 (38.6\%) with two, 52 (25.7\%) with three, 22 (10.9\%) with four, and six patients (3.0\%) with five other distant organ metastases. One patient $(0.5 \%)$ had more than six other distant organ metastases at the time of diagnosis of skeletal metastasis. Distant 
Table 1 Demographic data of patients with skeletal metastasis from lung cancer

\begin{tabular}{|c|c|c|c|c|c|c|}
\hline & & & Lung cancer surviv & & Skeletal metastasis & ival \\
\hline & Patients, n (\%) & & Survival (months) & $p$-value & Survival (months) & $p$-value \\
\hline Age, years & & & & & & \\
\hline$<60$ & $88(43.6 \%)$ & & 13.8 & 0.009 & 11.0 & 0.002 \\
\hline$\geq 60$ & $114(56.4 \%)$ & & 10.8 & & 8.8 & \\
\hline Sex & & & & & & \\
\hline Male & $126(62.4 \%)$ & & 12.2 & 0.850 & 9.5 & 0.327 \\
\hline Female & $76(37.6 \%)$ & & 11.9 & & 10.2 & \\
\hline Pathology & & & & & & \\
\hline Adenocarcinoma & $116(57.4 \%)$ & NSCLC & 12.6 & 0.080 & 10.4 & 0.000 \\
\hline Squamous cell carcinoma & $29(14.4 \%)$ & & & & & \\
\hline Large cell and other type lung cancer & $20(9.9 \%)$ & & & & & \\
\hline Small cell lung cancer & $37(18.3 \%)$ & SCLC & 10.0 & & 7.2 & \\
\hline Smoking & & & & & & \\
\hline Smoker & $114(56.4 \%)$ & & 12.0 & 0.968 & 9.4 & 0.216 \\
\hline Non-smoker & $88(43.6 \%)$ & & 12.1 & & 10.3 & \\
\hline Hypertension & & & & & & \\
\hline No & $152(75.2 \%)$ & & 11.9 & 0.545 & 9.6 & 0.421 \\
\hline Yes & $50(24.8 \%)$ & & 12.7 & & 10.2 & \\
\hline Diabetic Mellitus & & & & & & \\
\hline No & $176(87.1 \%)$ & & 11.9 & 0.400 & 9.6 & 0.332 \\
\hline Yes & $26(12.9 \%)$ & & 13.3 & & 10.6 & \\
\hline Chronic renal failure & & & & & & \\
\hline No & 199 (98.5\%) & & 12.1 & 0.960 & 9.7 & 0.370 \\
\hline Yes & $3(1.5 \%)$ & & 12.3 & & 12.3 & \\
\hline Chemotherapy & & & & & & \\
\hline Do & $192(95 \%)$ & & 12.6 & 0.000 & 10.1 & 0.000 \\
\hline Undo & $10(5 \%)$ & & 3.2 & & 3.2 & \\
\hline Radiation therapy & & & & & & \\
\hline Do & $174(86.1 \%)$ & & 12.5 & 0.062 & 9.9 & 0.147 \\
\hline Undo & $28(13.9 \%)$ & & 9.5 & & 8.5 & \\
\hline Orthopedic surgery & & & & & & \\
\hline Do & $41(20.3 \%)$ & & 14.1 & 0.079 & 12.6 & 0.000 \\
\hline Undo & $161(79.7 \%)$ & & 11.6 & & 9.1 & \\
\hline
\end{tabular}

organ metastases included 20 cases involving the mediastinum, 69 of the liver, 177 involving the lymph nodes, 29 of the chest wall, 101 of the cranial cavity, 55 of the adrenal glands, and 28 cases involving the kidneys.

Lung cancer survival was 12.1 months (range: 1-44 months). After diagnosis of lung cancer, skeletal metastasis was found at a mean of 2.5 months (range: 0-27 months); other organ metastases were found at a mean of 2.9 months (range: 0-24 months) after diagnosis of lung cancer. Orthopedic surgical treatment was performed in 41 patients (20.3\%). At the last follow-up, 166 patients $(82.20 \%)$ had died; skeletal metastasis survival was 9.8 months (range: $1-24$ months).

Among patients diagnosed with skeletal metastasis, patients younger than 60 years survived an average of 13.8 months, and those aged 60 years or older survived an average of 10.8 months after diagnosis of lung cancer $(p=0.009)$. After diagnosis of skeletal metastasis, patients younger than 60 years survived an average of 11.0 months, and those aged 60 years or older survived an average of 8.8 months $(p=0.002)$. 


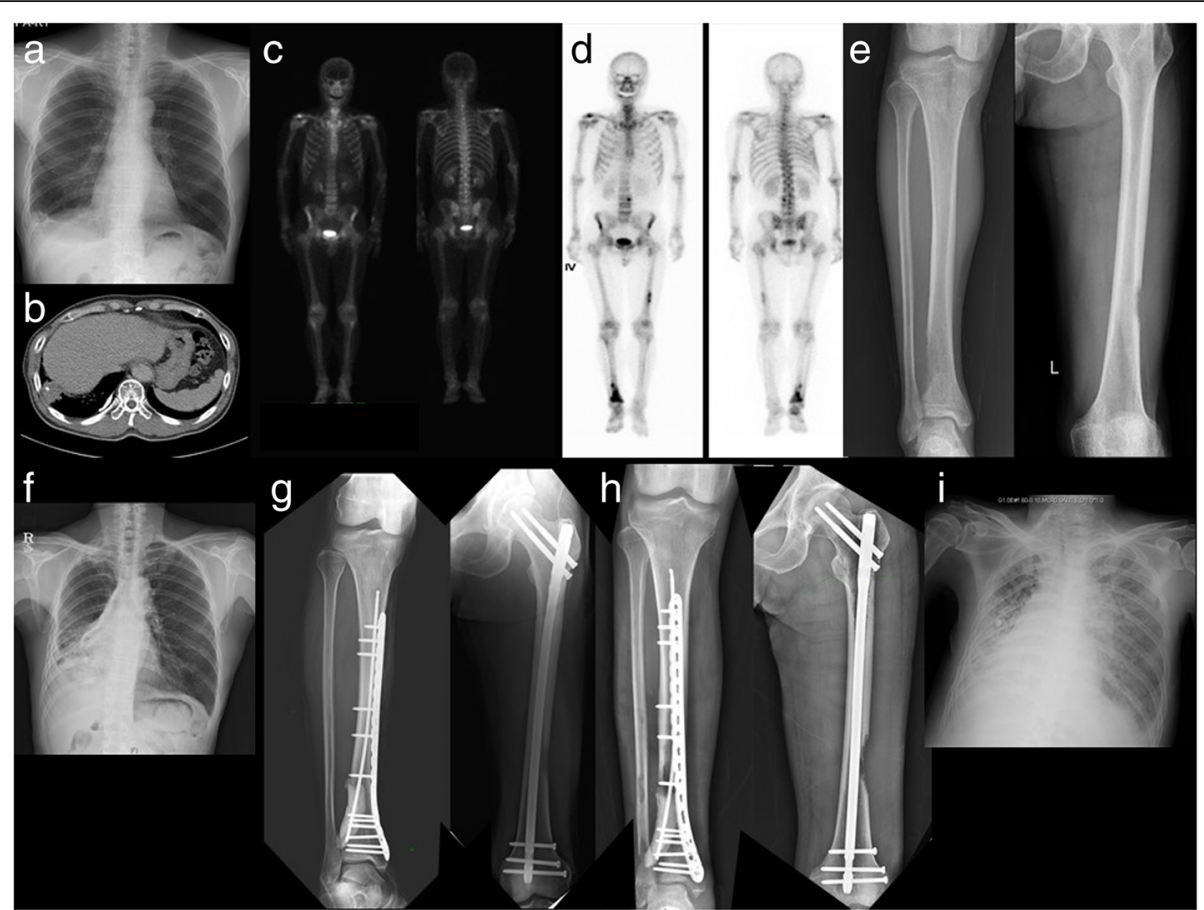

Fig. 1 A 66-year-old man who visited our hospital for hemoptysis. a Chest X-ray showed right costo-phrenic angle blurring. b Chest CT scan showed a 4 cm-sized mass. Squamous cell carcinoma was diagnosed by bronchoscopic biopsy. c At the time of diagnosis, the stage was T3N2M0. d At follow-up, WBBS was performed at 20 months of diagnosis, and hot-uptake was observed at the 2nd Lumbar body, left distal femur diaphysis and right distal tibia diaphysis. e The osteolytic lesions are observed in the lateral cortex of the left femur diaphysis and lateral cortex of right tibia diaphysis, suggesting skeletal metastases. $\mathbf{f}$ In chest X-ray, the haziness was increased at the right mid and lower lung field. $\mathbf{g}$ Curettage, flexible intramedullary nailing, plate fixation and bone cementing were performed on the right distal tibia diaphysis metastasis. Interlocking intramedullary nailing was performed on the left femur distal diaphysis metastasis. Additional postoperative radiation therapy was performed, and chemotherapy was continued. $\mathbf{h}$ Ten months after surgery, there was a slight increase in the size of the osteolytic lesions around the surgical sites, but full weight bearing without pain was possible. $\mathbf{i}$ The patient expired from pneumonia associated with lung cancer

After the diagnosis of lung cancer, the average survival rate was 12.2 months in male patients and 11.9 months in female patients $(p=0.850)$. Males survived an average of 9.5 months and females survived an average of 10.2 months after skeletal metastasis diagnosis $(p=0.327)$. After a diagnosis of lung cancer, the 114 patients with a smoking history (56.4\%) survived an average of 12.0 months, and the 88 patients with no smoking history survived an average of 12.1 months $(p=0.968)$. Patients with non-small cell lung cancer (NSCLC) survived an average of 12.6 months after diagnosis of lung cancer, and those with small-cell carcinoma survived an average of 10.0 months $(p=0.080)$. Patients with NSCLC survived an average of 10.4 months after diagnosis of skeletal metastasis, and those with small-cell carcinoma survived an average of 7.2 months $(p=0.000)$. We could not find any statistical significances in lung cancer survival and skeletal metastasis survival in patients with and without hypertension, diabetic mellitus, chronic renal failure (Table 1).
One hundred ninety-two patients (95\%) underwent chemotherapy for skeletal metastasis, and their lung cancer survival was 12.6 months. Lung cancer survival in 10 patients $(5 \%)$ without chemotherapy was 3.2 months $(p<$ 0.000 ). The skeletal metastasis survival of patients who underwent chemotherapy for skeletal metastasis was 10.1 months, and the skeletal metastasis survival of patients who were not treated with chemotherapy was 3.2 months $(p<0.000)$. One hundred seventy-four patients $(86.1 \%)$ underwent radiation therapy for skeletal metastasis, and their lung cancer survival was 12.5 months. Lung cancer survival in 28 patients (13.9\%) without radiation therapy was 9.5 months $(p=0.062)$. The skeletal metastasis survival of patients who underwent radiation therapy for skeletal metastasis was 9.9 months, and the skeletal metastasis survival of patients who were not treated with radiation was 8.5 months $(p=0.147)$.

Forty-one patients (20.3\%) underwent orthopedic surgery for pathologic fractures or impending fractures secondary to the underlying skeletal metastasis from lung cancer. The average age of patients with a diagnosis of 
lung cancer who underwent orthopedic surgery was 59.7 years; the average age of patients who did not have surgery was 61.4 years $(p=0.374)$. Mean lung cancer survival of patients who underwent orthopedic surgery was 14.1 months, and mean lung cancer survival was 11.6 months in patients without surgery $(p=0.079)$. Mean skeletal metastasis survival in patients who underwent surgery was 12.6 months; without surgery, mean survival after diagnosis of skeletal metastasis was 9.1 months $(p$ $<0.000$ ) (Table 1).

\section{Univariate and multivariate regression analysis of lung cancer survival}

Lung cancer diagnosed under 60 years of age [HR $\left(\begin{array}{ll}95 \% & C I\end{array}\right) 1.538$ (1.159-2.161), $\left.p=0.002\right]$, small cell lung cancer pathology type [HR $\left(\begin{array}{lll}95 \% & C I\end{array}\right) \quad 1.630$ (1.114-2.385), $p=0.008]$, chemotherapy for skeletal metastasis [HR (95\% CI) 9.827 (4.939-19.552), $p<$ $0.000]$, and radiation therapy for skeletal metastasis [HR $(95 \%$ CI $) 1.597 \quad(1.048-2.434), p=0.021]$ were significantly associated with longer lung cancer survival (Fig. 2). In addition, the multivariate analysis performed to determine which factors were an independent prognostic factor revealed that age under 60 years at diagnosis [HR (95\% CI) 1.549 (1.122-2.139), $\mathrm{p}=0.008]$, small cell lung cancer pathology type [HR (95\% CI) 1.711 (1.157-2.532), $p=0.007]$, chemotherapy for skeletal metastasis [HR $\left(\begin{array}{llll}95 \% & \mathrm{CI}\end{array}\right) 8.064$ (3.981-16.332), $p<0.000]$, and radiation therapy for skeletal metastasis [HR (95\% CI) 1.791 (1.170-2.742), $p=0.007]$ were significant independent prognostic factors (Table 2).

Univariate and multivariate regression analysis of skeletal metastasis survival

The following factors were significantly associated with longer skeletal metastasis survival: lung cancer diagnosed under 60 years of age [HR (95\% CI) 1.619 (1.1832.216), $p=0.002$ ], small cell lung cancer pathology type $\left.\left[\begin{array}{lllll}\mathrm{HR} & (95 \% & \mathrm{CI}\end{array}\right) \quad 1.950 \quad(1.309-2.904), \quad p<0.000\right]$,
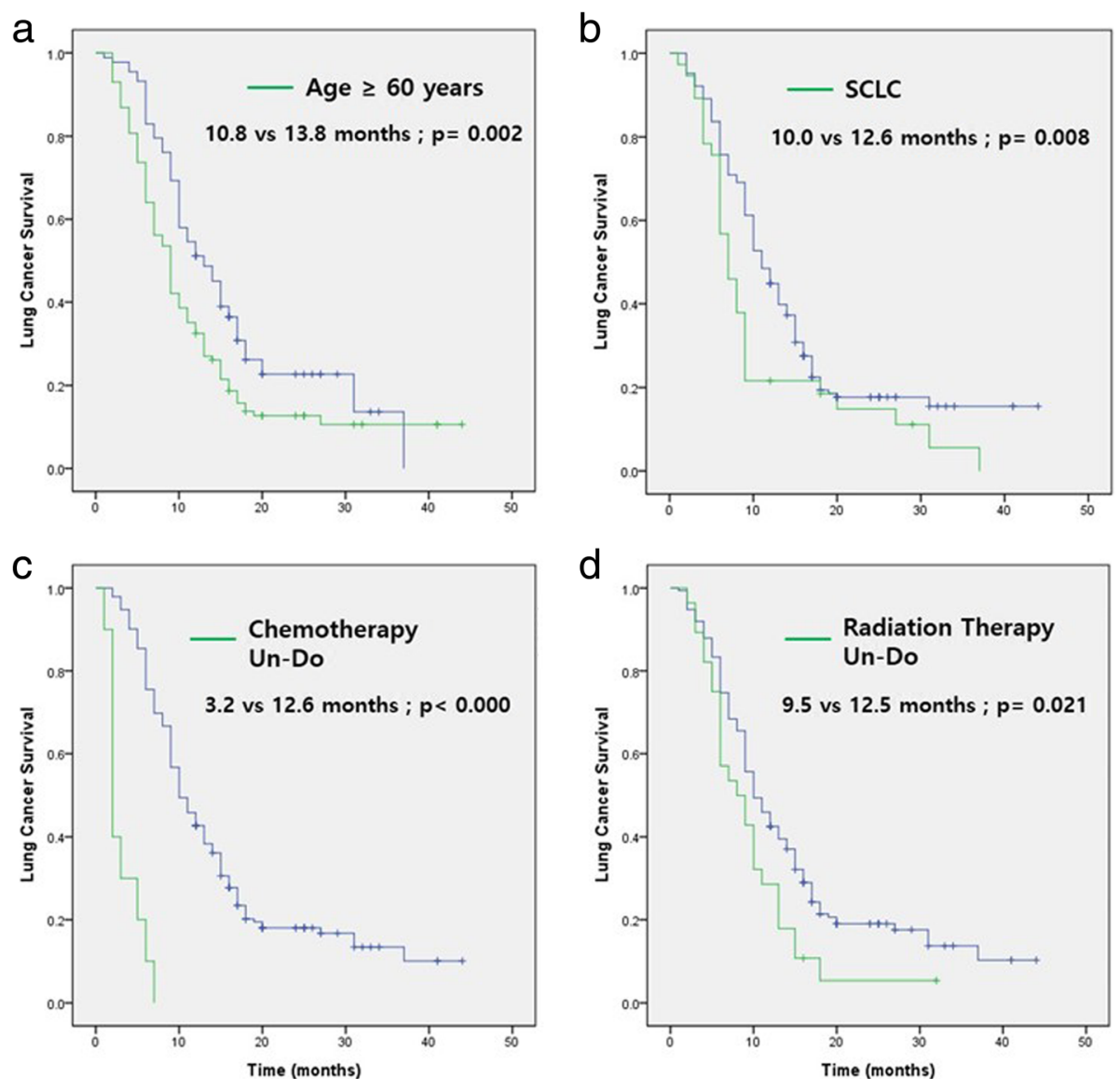

Fig. 2 Kaplan-Meier plots of lung cancer survival according to a) age at diagnosis of lung cancer, b) pathologic type of lung cancer, $\mathbf{c})$ whether chemotherapy was performed for skeletal metastasis, and $\mathbf{d}$ ) whether radiation therapy was performed for skeletal metastasis. Median survivals are expressed in months. Statistical significance was assessed by the log-rank test 
Table 2 Univariate and multivariate regression analysis of lung cancer survival

\begin{tabular}{|c|c|c|c|c|c|c|}
\hline \multirow[t]{2}{*}{ Variable } & \multicolumn{3}{|c|}{ Univariate analysis } & \multicolumn{3}{|c|}{ Multivariate analysis } \\
\hline & $\mathrm{HR}$ & $95 \% \mathrm{Cl}$ & $p$-value & $\mathrm{HR}$ & $95 \% \mathrm{Cl}$ & $p$-value \\
\hline Age $(<60$ vs. $\geq 60)$ & 1.538 & $1.159-2.161$ & 0.002 & 1.549 & $1.122-2.139$ & 0.008 \\
\hline Sex (male vs. female) & 1.086 & $0.790-1.492$ & 0.595 & & & \\
\hline Smoking (nonsmoker vs. smoker) & 1.114 & $0.818-1.517$ & 0.473 & & & \\
\hline Pathology (NSCLC vs. SCLC) & 1.630 & $1.114-2.385$ & 0.008 & 1.711 & $1.157-2.532$ & 0.007 \\
\hline EGFR (positive vs. negative) & 1.462 & $0.769-2.780$ & 0.225 & & & \\
\hline Number of distant organ metastasis (only 1 vs. over 2) & 1.177 & $0.812-1.705$ & 0.367 & & & \\
\hline Chemotherapy (yes vs. no) & 9.827 & 4.939-19.552 & 0.000 & 8.064 & $3.981-16.332$ & 0.000 \\
\hline Radiation therapy (yes vs. no) & 1.597 & $1.048-2.434$ & 0.021 & 1.791 & $1.170-2.742$ & 0.007 \\
\hline Orthopedic surgery (yes vs. no) & 1.377 & $0.931-2.036$ & 0.092 & & & \\
\hline
\end{tabular}

chemotherapy for skeletal metastasis [HR (95\% CI) 9.155 (4.584-18.284), $p<0.000$ ], and orthopedic surgical treatment for skeletal metastasis [HR (95\% CI) 1.691 (1.1422.504), $p=0.005$ ] (Fig. 3). In addition, the multivariate analysis performed to determine which factors were an independent prognostic factor revealed that age under
60 years at diagnosis [HR (95\% CI) 1.549 (1.124-2.134), $p=0.007]$, small cell lung cancer pathology type [HR (95\% CI) 2.045 (1.373-3.047), $p<0.000$ ], chemotherapy for skeletal metastasis [HR (95\% CI) 7.121 (3.54214.317), $p<0.000$ ], and orthopedic surgical treatment for skeletal metastasis [HR (95\% CI) 1.710 (1.148-2.547), p
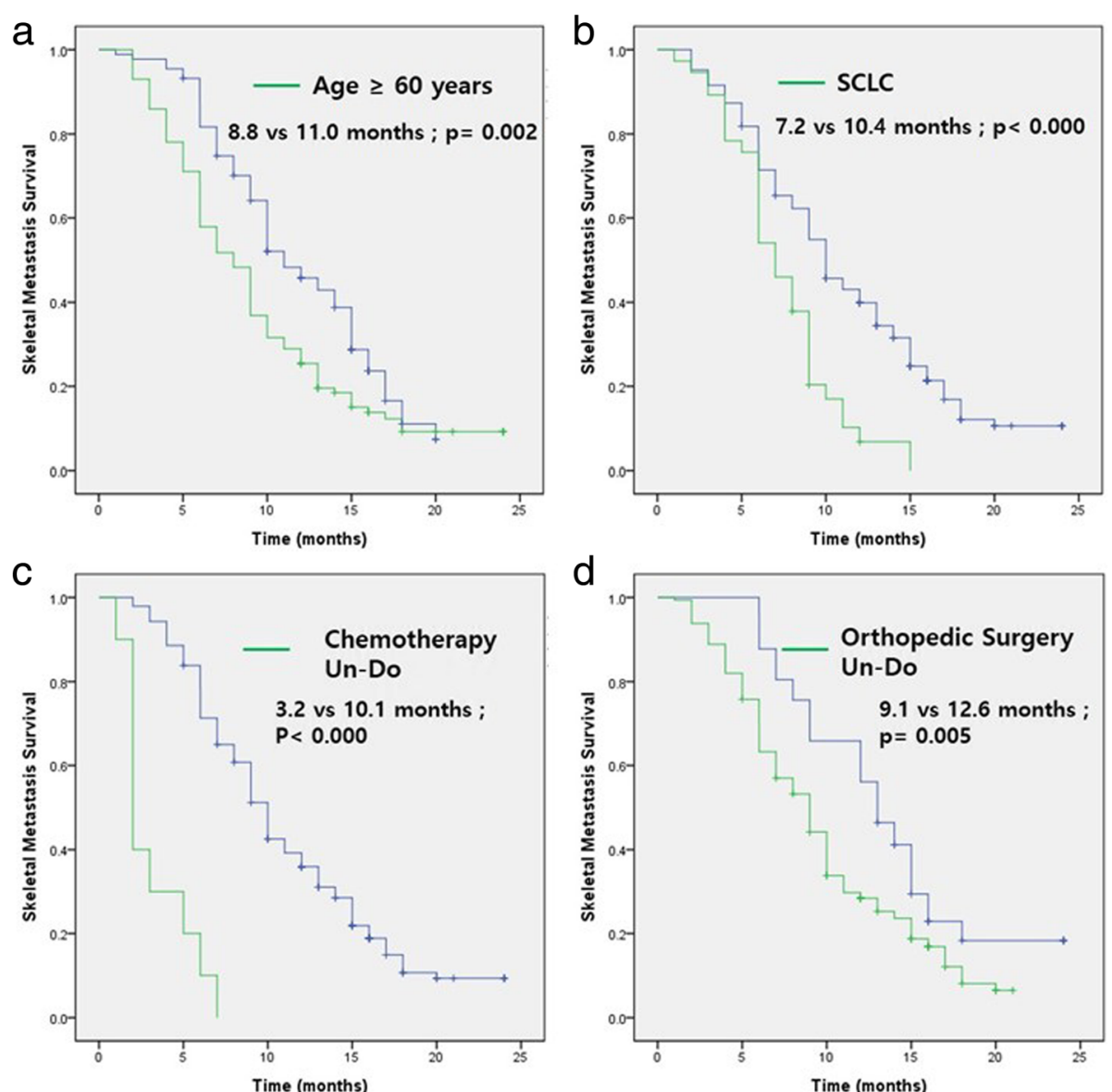

Fig. 3 Kaplan-Meier plots of skeletal metastasis survival in a) age at diagnosis of lung cancer, b) pathologic type of lung cancer, c) whether chemotherapy was performed for skeletal metastasis, and $\mathbf{d}$ ) whether orthopedic surgery was performed for skeletal metastasis. Median survivals are expressed in months. Statistical significance was assessed by the log-rank test 
Table 3 Univariate and multivariate regression analysis of skeletal metastasis survival

\begin{tabular}{|c|c|c|c|c|c|c|}
\hline \multirow[t]{2}{*}{ Variable } & \multicolumn{3}{|c|}{ Univariate analysis } & \multicolumn{3}{|c|}{ Multivariate analysis } \\
\hline & $\mathrm{HR}$ & $95 \% \mathrm{Cl}$ & $P$-value & $\mathrm{HR}$ & $95 \% \mathrm{Cl}$ & $P$-value \\
\hline Age (< 60 vs. $\geq 60)$ & 1.619 & $1.183-2.216$ & 0.002 & 1.549 & $1.124-2.134$ & 0.007 \\
\hline Sex (male vs. female) & 1.157 & $0.843-1.587$ & 0.338 & & & \\
\hline Smoking (nonsmoker vs. smoker) & 1.189 & $0.870-1.623$ & 0.141 & & & \\
\hline Pathology (NSCLC vs. SCLC) & 1.950 & $1.309-2.904$ & 0.000 & 2.045 & $1.373-3.047$ & 0.000 \\
\hline EGFR (positive vs. negative) & 1.479 & $0.772-2.833$ & 0.208 & & & \\
\hline Number of distant organ metastasis (only 1 vs. over 2) & 1.058 & $0.722-1.550$ & 0.247 & & & \\
\hline Chemotherapy (yes vs. no) & 9.155 & $4.584-18.284$ & 0.000 & 7.121 & $3.542-14.317$ & 0.000 \\
\hline Radiation therapy (yes vs. no) & 1.291 & $0.840-1.982$ & 0.059 & & & \\
\hline Orthopedic surgery (yes vs. no) & 1.691 & $1.142-2.504$ & 0.005 & 1.710 & $1.148-2.547$ & 0.008 \\
\hline
\end{tabular}

$=0.008]$ were significant independent prognostic factors (Table 3).

\section{Discussion}

Majority $(\sim 50 \%)$ of lung cancer patients suffer from bone metastases, mainly spine and rib involvement.

$[13,14]$. In a cohort study of 112 patients with lung cancer who had bone metastases, metastatic spinal cord compression (MSCC) occurred in 31cases (27.7\%). Patients with MSCC had a 6.1 times greater risk of developing MSCC and poor median survival (4.4 months) and the medial survival time after the occurrence of MSCC was 2.8 months [15]. Possible mechanism of spinal metastasis is access to the vertebral bodies in the thoracic and lumbar spine through the plexus vertebral system and the high bone marrow flow of some skeletal elements $[16,17]$. Spine metastasis of lung cancer has been described in several papers, and survival has been relatively well analyzed. Therefore, in this presented article, we discuss pure appendicular skeletal metastasis of lung cancer, except spine metastasis.

The presence of osteolytic lesions leads to weakeness of bone tissue and leads to the emergence of SREs, including hypercalcemia, pathologic fractures, and compression fractures of the spine that might require treatment [18]. Systemic therapies that block osteoclast activity, including bisphosphonates (zoledronic acid) and receptor activator for nuclear factor- $\mathrm{\kappa} \beta$ ligand (RANKL) inhibitors (denosumab), is known to reduce the incidence of SREs, but they have a modest impact on survival [10]. Denosumab demonstrated superior efficacy than zoledronic acid in delaying the appearance of SREs in NSCLC in a randomized trial; however, denosumab showed no differences regarding osteonecrosis of the jaw, a serious complication encountered in patients treated long-term $[19,20]$.

Approximately two-thirds of all patients with lung cancer have advanced disease at the time of diagnosis, and these patients are known to have low long-term survival rates. Patients with a lung cancer survival of more than 2 years are reclassified as belonging to the long-term survival group. In long-term survival groups, the survival period can be increased by using different treatment modalities [21-24]. Long-term survivors account for $7.2-12.8 \%$ of all patients with advanced lung cancer, and stage and performance status are significant factors in these patients [24-27]. In general, the prognostic factors in metastatic tumors of the skeletal system are performance status, number of skeletal metastases, pain level, and primary carcinoma; in patients with lung cancer, breast cancer, and prostate cancer, these are different from each other [28-33]. In a previous study, Sugiura et al. suggested prognostic factors, including histologic diagnosis, skeletal metastasis location, and use of EGFR-targeted agents, in the prognosis of 118 patients with lung cancer who had skeletal metastasis [13]. In this study, only 71 cases of EGFR mutation were investigated, this is because it is a subject collected from 2005 to 2015. EGFR mutation has been actively investigated since 2011 in South Korea. We investigated the patients with skeletal metastasis. Therefor we do not have control, the patient without skeletal metastasis, to compare whether the EGFR mutation is a risk factor for developing skeletal metastasis. The number of metastatic sites, timing of recurrence, histologic adenocarcinoma, and treatment modality for metastatic tumors are known to be significant prognostic factors for recurrent lung cancer [34-36]. In this study, survival after the diagnosis of skeletal metastasis is discussed, so the results are somewhat different for the factors affecting survival rates.

In the treatment principles of pathologic fractures of the long bones, bone dissemination can be grouped into three categories: solitary lesion, oligometastases, or diffuse. Solitary lesions can be treated with curative measures. Especially for patients with kidney and breast 
cancers, it is hypothesized that more aggressive local treatment might improve survival in the case of oligometastases [37]. However, skeletal metastasis from lung cancer is generally treated palliatively. This tendency is due to the fact that patients with lung cancer have more frequent and more severe pulmonary dysfunction, affecting their ability to tolerate general anesthesia for orthopedic surgery. Moreover, the lifespan in patients with lung cancer is not as long as that in patients with breast or kidney cancers. If orthopedic surgery is planned, comprehensive anesthetic plan should be established including laboratory studies and accurate lung function should be evaluated using high-resolution $\mathrm{CT}$ and pulmonary function. A surgical approach to skeletal metastasis is possible if partial anesthesia, including nerve plexus block, is appropriately used. The first step of treatment strategy is to decide whether surgery is required, and this should be determined in a multidisciplinary meeting. Radiotherapy should be considered as standard treatment for small lesions, whereas surgery is useful for actual fractures and impending fractures. The purpose of all treatments is to maintain optimal pain-free function of the extremities and direct weight bearing and mobility. Based on prospective researches, axial cortical involvement of $>30 \mathrm{~mm}$ and circumferential cortical involvement of $>50 \%$ is considered as risk factors for fracture [38]. The next step is to decide the fixation types. After orthopedic surgery, the expected lifetime and the implant types are important issues. It is fortunate if the implant survives until the patient dies. If the implant wears out before the patient dies, additional decision-making is necessary, including whether to reoperate. The rigid fixation should be durable enough to use during remaining lifetime of the patient, and recovery time should not exceed the life expectancy of the fixation. The aim of our study is to provide the strategy for lung cancer patient with skeletal metastasis. For the patients expected survival is less than 6 weeks, the possible benefits of surgical intervention must be strongly considered and conservative care should be sought. For the cases need absolute requirement for surgical intervention, minimally invasive surgery is needed with short recovery time. For patients with an expected short-term survival (between 6 weeks and 6 months), more invasive procedures are warranted. However, the use of extensive reconstruction or large, complication-prone prostheses should not be considered. For cases with long-term survivor who expected more than 6 months needs comprehensive surgery [39]. Our findings revealed that there was no statistically significant difference in survival after the diagnosis of primary lung cancer between our patient groups. However, survival after diagnosis of skeletal metastasis from lung cancer was significantly longer in patients who underwent orthopedic surgery for skeletal metastasis of lung cancer than in patients who did not receive surgery for skeletal metastasis. Decisions about whether to perform orthopedic surgery for skeletal metastasis were made using the flowchart shown in Fig. 4. Of the 161 patients who did not undergo orthopedic surgery for skeletal metastasis, 9 (5.6\%) survived less than 6 weeks; 1 patient $(2.4 \%)$ had undergone other surgery but died in less than 6 weeks. It may not be possible to exclude the possibility of selection bias from the present study, but this is a limitation of prospective

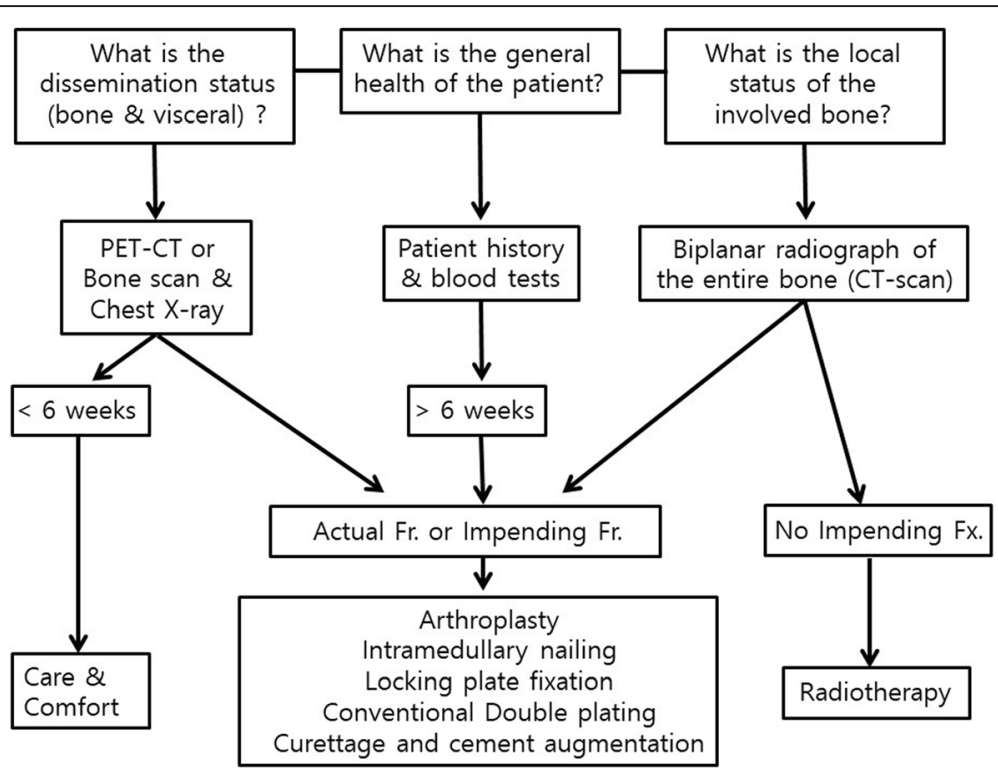

Fig. 4 Decision-making diagram for skeletal metastasis in patients with lung cancer 
studies. However, it should be understood that this difference was not statistically significant, and we have attempted to comply with standard procedures in decision-making (Fig. 4).

\section{Conclusion}

In our study, we had good prognostic factor for longer survival (less than 60 years old, chemotherapy as treatment for skeletal metastasis, NSCLC rather than SCLC, and underwent orthopedic surgery for skeletal metastasis). Patients died sooner if they had skeletal metastasis at the time of diagnosis of primary lung cancer. Patients with skeletal metastasis from primary lung cancer should be supported in developing a deeper understanding of appropriate treatment to improve their survival and quality of life.

\section{Abbreviations}

Cl: Confidence interval; CT: Computed tomography; EGFR: Epidermal growth factor receptor; Fx: Fracture; HR: Hazard ratio; MRI: Magnetic resonance imaging; MSCC: Metastatic spinal cord compression; NSCLC: Non-small cell lung cancer; OR: Odds ratio; PET-CT: Positron emission tomographycomputed tomography; SCLC: Small-cell lung cancer; SRE: Skeletal-related event; WBBS: Whole body bone scan

\section{Acknowledgements}

Not applicable.

\section{Funding}

This study was supported by a research fund from Chosun University, 2018 The funders had no role in the study design, data collection and anlaysis, decision to publish or preparation of the manuscript

\section{Availability of data and materials}

These data are available to researchers. The researcher who wants to get the data can contact the 1st author, Yong Jin Cho.

\section{Author's contributions}

YJC, HSK conceived and designed the research. YMC, SHK, KHS and STJ collected the data. YJC performed the statistical analysis. YJC wrote the paper. All authors read and approved the final manuscripts.

\section{Competing interest}

The authors declare that they have no competing interest.

\section{Ethics approval and consent to participate}

This study was approved by the Institutional Review Board of Chosun University Hospital (2018-05-005-002), Chonnam University Hospital (CNUH2018-147), and Severence Hospital (4-5017-550). A prior signed informed consent was obtained from each patient. All of the procedures were performed in accordance with the relevant policies in South Korea and adhered to the tenets of the Declaration of Helsinki.

\section{Consent for publication}

Not applicable.

\section{Publisher's Note}

Springer Nature remains neutral with regard to jurisdictional claims in published maps and institutional affiliations.

\section{Author details}

'Department of Orthopedic Surgery, Chosun University College of Medicine, Gwangju, South Korea. ${ }^{2}$ Department of Orthopedic Surgery, Yonsei University College of Medicine, Seoul, South Korea. ${ }^{3}$ Department of Orthopedic Surgery, Chonnam National University College of Medicine, Gwangju, South Korea.

${ }^{4}$ Division of Medical Oncology, Department of Internal Medicine, Yonsei
University College of Medicine, 134 Shinchondong, Seodaemun-gu, Seou 120-752, South Korea.

Received: 5 September 2018 Accepted: 27 March 2019

Published online: 03 April 2019

\section{References}

1. Devesa SS, Bray F, Vizcaino AP, Parkin DM. International lung cancer trends by histologic type: male:female differences diminishing and adenocarcinoma rates rising. Int J Cancer. 2005;117(2):294-9.

2. Siegel R, Naishadham D, Jemal A. Cancer statistics, 2013. CA Cancer J Clin. 2013;63(1):11-30.

3. Chen W, Zheng R, Baade PD, Zhang S, Zeng H, Bray F, Jemal $A, Y u X Q, H e J$. Cancer statistics in China, 2015. CA Cancer J Clin. 2016;66(2):115-32.

4. Rosen LS, Gordon D, Tchekmedyian NS, Yanagihara R, Hirsh V, Krzakowski M, Pawlicki M, De Souza P, Zheng M, Urbanowitz G, et al. Long-term efficacy and safety of zoledronic acid in the treatment of skeletal metastases in patients with nonsmall cell lung carcinoma and other solid tumors: a randomized, phase III, double-blind, placebo-controlled trial. Cancer. 2004; 100(12):2613-21.

5. Price N. Bisphosphonates to prevent skeletal morbidity in patients with lung cancer with bone metastases. Clin Lung Cancer. 2004;5(5):267-9.

6. Delea TE, McKiernan J, Brandman J, Edelsberg J, Sung J, Raut M, Oster G. Impact of skeletal complications on total medical care costs among patients with bone metastases of lung cancer. J Thorac Oncol. 2006;1(6):571-6.

7. Langer C, Hirsh V. Skeletal morbidity in lung cancer patients with bone metastases: demonstrating the need for early diagnosis and treatment with bisphosphonates. Lung cancer (Amsterdam, Netherlands). 2010;67(1):4-11.

8. Coleman RE, Smith P, Rubens RD. Clinical course and prognostic factors following bone recurrence from breast cancer. Br J Cancer. 1998;77(2):33640.

9. Ibrahim T, Mercatali L, Amadori D. Bone and cancer: the osteoncology. Clin Cases Miner Bone Metab. 2013:10(2):121-3.

10. Lopez-Olivo MA, Shah NA, Pratt G, Risser JM, Symanski E, Suarez-Almazor ME. Bisphosphonates in the treatment of patients with lung cancer and metastatic bone disease: a systematic review and meta-analysis. Support Care Cancer. 2012:20(11):2985-98.

11. Zhang L, Gong Z. Clinical characteristics and prognostic factors in bone metastases from lung Cancer. Med Sci Monit. 2017;23:4087-94.

12. Chambard L, Girard N, Ollier E, Rousseau JC, Duboeuf F, Carlier MC, Brevet M, Szulc P, Pialat JB, Wegrzyn J, et al. Bone, muscle, and metabolic parameters predict survival in patients with synchronous bone metastases from lung cancers. Bone. 2018:108:202-9.

13. Sugiura H, Yamada K, Sugiura T, Hida T, Mitsudomi T. Predictors of survival in patients with bone metastasis of lung cancer. Clin Orthop Relat Res. 2008;466(3):729-36.

14. Tsuya A, Kurata T, Tamura K, Fukuoka M. Skeletal metastases in non-small cell lung cancer: a retrospective study. Lung Cancer (Amsterdam, Netherlands). 2007;57(2):229-32.

15. Silva GT, Bergmann A, Thuler LC. Incidence, associated factors, and survival in metastatic spinal cord compression secondary to lung cancer. Spine J. 2015:15(6):1263-9.

16. Batson OV. The function of the vertebral veins and their role in the spread of metastases. Ann Surg. 1940;112(1):138-49.

17. Kahn D, Weiner GJ, Ben-Haim S, Ponto LL, Madsen MT, Bushnell DL, Watkins GL, Argenyi EA, Hichwa RD. Positron emission tomographic measurement of bone marrow blood flow to the pelvis and lumbar vertebrae in young normal adults. Blood. 1994;83(4):958-63.

18. Coleman RE. Management of bone metastases. Oncologist. 2000;5(6):46370.

19. Henry DH, Costa L, Goldwasser F, Hirsh V, Hungria V, Prausova J, Scagliotti GV, Sleeboom H, Spencer A, Vadhan-Raj S, et al. Randomized, double-blind study of denosumab versus zoledronic acid in the treatment of bone metastases in patients with advanced cancer (excluding breast and prostate cancer) or multiple myeloma. J Clin Oncol. 2011;29(9):1125-32.

20. Scagliotti GV, Hirsh V, Siena S, Henry DH, Woll PJ, Manegold C, Solal-Celigny P, Rodriguez G, Krzakowski M, Mehta ND, et al. Overall survival improvement in patients with lung cancer and bone metastases treated with denosumab versus zoledronic acid: subgroup analysis from a randomized phase 3 study. J Thorac Oncol. 2012;7(12):1823-9. 
21. Scagliotti GV, Parikh P, von Pawel J, Biesma B, Vansteenkiste J, Manegold C, Serwatowski P, Gatzemeier U, Digumarti R, Zukin M, et al. Phase III study comparing cisplatin plus gemcitabine with cisplatin plus pemetrexed in chemotherapy-naive patients with advanced-stage non-small-cell lung cancer. J Clin Oncol. 2008;26(21):3543-51.

22. Sandler A, Gray R, Perry MC, Brahmer J, Schiller JH, Dowlati A, Lilenbaum R, Johnson DH. Paclitaxel-carboplatin alone or with bevacizumab for nonsmall-cell lung cancer. N Engl J Med. 2006;355(24):2542-50.

23. Satoh H, Ishikawa H, Yamashita YT, Naito T, Takahashi H, Kamma H, Ohtsuka $\mathrm{M}$, Hasegawa $\mathrm{S}$. Analysis of long-term survivors after platinum containing chemotherapy in advanced non-small cell lung cancer. Anticancer Res. 1998;18(2b):1295-8.

24. Satoh H, Ishikawa H, Ohara G, Kagohashi K, Kurishima K, Ohtsuka M, Hizawa N. Long-term survivors after chemotherapy in advanced non-small cell lung cancer. Anticancer Res. 2007:27(6c):4457-60.

25. Le Chevalier T, Brisgand D, Soria JC, Douillard JY, Pujol JL, Ruffie P, Aberola $\mathrm{V}$, Cigolari S. Long term analysis of survival in the European randomized trial comparing vinorelbine/cisplatin to vindesine/cisplatin and vinorelbine alone in advanced non-small cell lung cancer. Oncologist. 2001;6(Suppl 1):8-11.

26. Kojima A, Shinkai T, Eguchi K, Sasaki Y, Tamura T, Ohe Y, Oshita F, Miya T, Okamoto $\mathrm{H}$, Kondo $\mathrm{H}$, et al. Analysis of three-year survivors among patients with advanced inoperable non-small cell lung cancer. Jpn J Clin Oncol. 1991;21(4):276-81.

27. Caglayan B, Fidan A, Salepci B, Kiral N, Torun E, Salepci T, Mayadagli A. Effects of prognostic factors and treatment on survival in advanced nonsmall cell lung cancer. Tuberkuloz ve toraks. 2004;52(4):323-32.

28. Niewald M, Tkocz HJ, Abel U, Scheib T, Walter K, Nieder C, Schnabel K, Berberich W, Kubale R, Fuchs M. Rapid course radiation therapy vs. more standard treatment: a randomized trial for bone metastases. Int J Radiat Oncol Biol Phys. 1996;36(5):1085-9.

29. Tong D, Gillick L, Hendrickson FR. The palliation of symptomatic osseous metastases: final results of the study by the radiation therapy oncology group. Cancer. 1982;50(5):893-9.

30. Coleman RE. Clinical features of metastatic bone disease and risk of skeletal morbidity. Clin Cancer Res. 2006;12(20 Pt 2):6243s-9s.

31. van der Linden YM, Steenland E, van Houwelingen HC, Post WJ, Oei B, Marijnen CA, Leer JW. Patients with a favourable prognosis are equally palliated with single and multiple fraction radiotherapy: results on survival in the Dutch bone metastasis study. Radiother Oncol. 2006;78(3):245-53.

32. Arcangeli G, Giovinazzo G, Saracino B, D'Angelo L, Giannarelli D, Arcangeli $G$, Micheli A. Radiation therapy in the management of symptomatic bone metastases: the effect of total dose and histology on pain relief and response duration. Int J Radiat Oncol Biol Phys. 1998;42(5):1119-26.

33. Coleman RE. Skeletal complications of malignancy. Cancer. 1997;80(8 Suppl): 1588-94.

34. Yoshino I, Yohena T, Kitajima M, Ushijima C, Nishioka K, Ichinose Y, Sugimachi K. Survival of non-small cell lung cancer patients with postoperative recurrence at distant organs. Ann Thorac Cardiovasc Surg. 2001;7(4):204-9.

35. Oh Y, Taylor S, Bekele BN, Debnam JM, Allen PK, Suki D, Sawaya R, Komaki R, Stewart DJ, Karp DD. Number of metastatic sites is a strong predictor of survival in patients with nonsmall cell lung cancer with or without brain metastases. Cancer. 2009;115(13):2930-8.

36. Yano T, Haro A, Yoshida T, Morodomi Y, Ito K, Shikada Y, Shoji F, Maruyama $R$, Maehara Y. Prognostic impact of local treatment against postoperative oligometastases in non-small cell lung cancer. J Surg Oncol. 2010;102(7): 852-5.

37. Di Lascio S, Pagani O. Oligometastatic breast cancer: a shift from palliative to potentially curative treatment? Breast care (Basel, Switzerland). 2014; 9(1):7-14.

38. van der Linden YM, Kroon HM, Dijkstra SP, Lok JJ, Noordijk EM, Leer JW, Marijnen CA. Simple radiographic parameter predicts fracturing in metastatic femoral bone lesions: results from a randomised trial. Radiother Oncol. 2003;69(1):21-31.

39. Willeumier JJ, van der Linden YM, van de Sande MAJ, Dijkstra PDS. Treatment of pathological fractures of the long bones. EFORT Open Rev. 2016;1(5):136-45.

Ready to submit your research? Choose BMC and benefit from:

- fast, convenient online submission

- thorough peer review by experienced researchers in your field

- rapid publication on acceptance

- support for research data, including large and complex data types

- gold Open Access which fosters wider collaboration and increased citations

- maximum visibility for your research: over $100 \mathrm{M}$ website views per year

At BMC, research is always in progress.

Learn more biomedcentral.com/submissions 